\title{
Research and trends in STEM education: a systematic review of journal publications
}

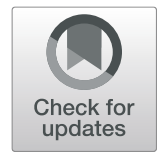

Yeping $\mathrm{Li}^{1^{*}}$, Ke Wang ${ }^{2}$, Yu Xiao ${ }^{1}$ and Jeffrey E. Froyd ${ }^{3}$

\begin{abstract}
With the rapid increase in the number of scholarly publications on STEM education in recent years, reviews of the status and trends in STEM education research internationally support the development of the field. For this review, we conducted a systematic analysis of 798 articles in STEM education published between 2000 and the end of 2018 in 36 journals to get an overview about developments in STEM education scholarship. We examined those selected journal publications both quantitatively and qualitatively, including the number of articles published, journals in which the articles were published, authorship nationality, and research topic and methods over the years. The results show that research in STEM education is increasing in importance internationally and that the identity of STEM education journals is becoming clearer over time.
\end{abstract}

Keywords: Journal publication, Literature review, Status, STEM education research, Trends

\section{Introduction}

A recent review of 144 publications in the International Journal of STEM Education (IJ-STEM) showed how scholarship in science, technology, engineering, and mathematics (STEM) education developed between August 2014 and the end of 2018 through the lens of one journal (Li, Froyd, \& Wang, 2019). The review of articles published in only one journal over a short period of time prompted the need to review the status and trends in STEM education research internationally by analyzing articles published in a wider range of journals over a longer period of time.

With global recognition of the growing importance of STEM education, we have witnessed the urgent need to support research and scholarship in STEM education (Li, 2014, 2018a). Researchers and educators have responded to this on-going call and published their scholarly work through many different publication outlets including journals, books, and conference proceedings. A simple Google search with the term "STEM," "STEM education," or "STEM education research" all returned more than 450,000,000 items. Such voluminous information shows the rapidly evolving and vibrant field of STEM education and sheds light on the volume of

\footnotetext{
* Correspondence: yepingli@tamu.edu

${ }^{1}$ Texas A\&M University, College Station, TX 77843-4232, USA

Full list of author information is available at the end of the article
}

STEM education research. In any field, it is important to know and understand the status and trends in scholarship for the field to develop and be appropriately supported. This applies to STEM education.

Conducting systematic reviews to explore the status and trends in specific disciplines is common in educational research. For example, researchers surveyed the historical development of research in mathematics education (Kilpatrick, 1992) and studied patterns in technology usage in mathematics education (Bray \& Tangney, 2017; Sokolowski, Li, \& Willson, 2015). In science education, Tsai and his colleagues have conducted a sequence of reviews of journal articles to synthesize research trends in every 5 years since 1998 (i.e., 1998-2002, 2003-2007, 2008-2012, and 2013-2017), based on publications in three main science education journals including, Science Education, the International Journal of Science Education, and the Journal of Research in Science Teaching (e.g., Lin, Lin, Potvin, \& Tsai, 2019; Tsai \& Wen, 2005). Erduran, Ozdem, and Park (2015) reviewed argumentation in science education research from 1998 to 2014 and Minner, Levy, and Century (2010) reviewed inquiry-based science instruction between 1984 and 2002. There are also many literature reviews and syntheses in engineering and technology education (e.g., Borrego, Foster, \& 
Froyd, 2015; Xu, Williams, Gu, \& Zhang, 2019). All of these reviews have been well received in different fields of traditional disciplinary education as they critically appraise and summarize the state-of-art of relevant research in a field in general or with a specific focus. Both types of reviews have been conducted with different methods for identifying, collecting, and analyzing relevant publications, and they differ in terms of review aim and topic scope, time period, and ways of literature selection. In this review, we systematically analyze journal publications in STEM education research to overview STEM education scholarship development broadly and globally.

\section{The complexity and ambiguity of examining the status and trends in STEM education research}

A review of research development in a field is relatively straight forward, when the field is mature and its scope can be well defined. Unlike discipline-based education research (DBER, National Research Council, 2012), STEM education is not a well-defined field. Conducting a comprehensive literature review of STEM education research require careful thought and clearly specified scope to tackle the complexity naturally associated with STEM education. In the following sub-sections, we provide some further discussion.

\section{Diverse perspectives about STEM and STEM education}

STEM education as explicated by the term does not have a long history. The interest in helping students learn across STEM fields can be traced back to the 1990s when the US National Science Foundation (NSF) formally included engineering and technology with science and mathematics in undergraduate and $\mathrm{K}-12$ school education (e.g., National Science Foundation, 1998). It coined the acronym SMET (science, mathematics, engineering, and technology) that was subsequently used by other agencies including the US Congress (e.g., United States Congress House Committee on Science, 1998). NSF also coined the acronym STEM to replace SMET (e.g., Christenson, 2011; Chute, 2009) and it has become the acronym of choice. However, a consensus has not been reached on the disciplines included within STEM.

To clarify its intent, NSF published a list of approved fields it considered under the umbrella of STEM (see http://bit.ly/2Bk1Yp5). The list not only includes disciplines widely considered under the STEM tent (called "core" disciplines, such as physics, chemistry, and materials research), but also includes disciplines in psychology and social sciences (e.g., political science, economics). However, NSF's list of STEM fields is inconsistent with other federal agencies. Gonzalez and Kuenzi (2012) noted that at least two US agencies, the Department of Homeland Security and Immigration and
Customs Enforcement, use a narrower definition that excludes social sciences. Researchers also view integration across different disciplines of STEM differently using various terms such as, multidisciplinary, interdisciplinary, and transdisciplinary (Vasquez, Sneider, \& Comer, 2013). These are only two examples of the ambiguity and complexity in describing and specifying what constitutes STEM.

Multiple perspectives about the meaning of STEM education adds further complexity to determining the extent to which scholarly activity can be categorized as STEM education. For example, STEM education can be viewed with a broad and inclusive perspective to include education in the individual disciplines of STEM, i.e., science education, technology education, engineering education, and mathematics education, as well as interdisciplinary or cross-disciplinary combinations of the individual STEM disciplines (English, 2016; Li, 2014). On the other hand, STEM education can be viewed by others as referring only to interdisciplinary or cross-disciplinary combinations of the individual STEM disciplines (Honey, Pearson, \& Schweingruber, 2014; Johnson, Peters-Burton, \& Moore, 2015; Kelley \& Knowles, 2016; Li, 2018a). These multiple perspectives allow scholars to publish articles in a vast array and diverse journals, as long as journals are willing to take the position as connected with STEM education. At the same time, however, the situation presents considerable challenges for researchers intending to locate, identify, and classify publications as STEM education research. To tackle such challenges, we tried to find out what we can learn from prior reviews related to STEM education.

\section{Guidance from prior reviews related to STEM education}

A search for reviews of STEM education research found multiple reviews that could suggest approaches for identifying publications (e.g., Brown, 2012; Henderson, Beach, \& Finkelstein, 2011; Kim, Sinatra, \& Seyranian, 2018; Margot \& Kettler, 2019; Minichiello, Hood, \& Harkness, 2018; Mizell \& Brown, 2016; Thibaut et al., 2018; Wu \& Rau, 2019). The review conducted by Brown (2012) examined the research base of STEM education. He addressed the complexity and ambiguity by confining the review with publications in eight journals, two in each individual discipline, one academic research journal (e.g., the Journal of Research in Science Teaching) and one practitioner journal (e.g., Science Teacher). Journals were selected based on suggestions from some faculty members and K-12 teachers. Out of 1100 articles published in these eight journals from January 1, 2007, to October 1, 2010, Brown located 60 articles that authors self-identified as connected to STEM education. He found that the vast majority of these 60 articles focused on issues beyond an individual discipline and 
there was a research base forming for STEM education. In a follow-up study, Mizell and Brown (2016) reviewed articles published from January 2013 to October 2015 in the same eight journals plus two additional journals. Mizell and Brown used the same criteria to identify and include articles that authors self-identified as connected to STEM education, i.e., if the authors included STEM in the title or author-supplied keywords. In comparison to Brown's findings, they found that many more STEM articles were published in a shorter time period and by scholars from many more different academic institutions. Taking together, both Brown (2012) and Mizell and Brown (2016) tended to suggest that STEM education mainly consists of interdisciplinary or crossdisciplinary combinations of the individual STEM disciplines, but their approach consisted of selecting a limited number of individual discipline-based journals and then selecting articles that authors self-identified as connected to STEM education.

In contrast to reviews on STEM education, in general, other reviews focused on specific issues in STEM education (e.g., Henderson et al., 2011; Kim et al., 2018; Margot \& Kettler, 2019; Minichiello et al., 2018; Schreffler, Vasquez III, Chini, \& James, 2019; Thibaut et al., 2018; Wu \& Rau, 2019). For example, the review by Henderson et al. (2011) focused on instructional change in undergraduate STEM courses based on 191 conceptual and empirical journal articles published between 1995 and 2008. Margot and Kettler (2019) focused on what is known about teachers' values, beliefs, perceived barriers, and needed support related to STEM education based on 25 empirical journal articles published between 2000 and 2016 . The focus of these reviews allowed the researchers to limit the number of articles considered, and they typically used keyword searches of selected databases to identify articles on STEM education. Some researchers used this approach to identify publications from journals only (e.g., Henderson et al., 2011; Margot \& Kettler, 2019; Schreffler et al., 2019), and others selected and reviewed publications beyond journals (e.g., Minichiello et al., 2018; Thibaut et al., 2018; Wu \& Rau, 2019).

\section{Summary}

The discussion in this section suggests possible reasons contributing to the absence of a general literature review of STEM education research and development: (1) diverse perspectives in existence about STEM and STEM education that contribute to the difficulty of specifying a scope of literature review, (2) its short but rapid development history in comparison to other discipline-based education (e.g., science education), and (3) difficulties in deciding how to establish the scope of the literature review. With respect to the third reason, prior reviews have used one of two approaches to identify and select articles: (a) identifying specific journals first and then searching and selecting specific articles from these journals (e.g., Brown, 2012; Erduran et al., 2015; Mizell \& Brown, 2016) and (b) conducting selected database searches with keywords based on a specific focus (e.g., Margot \& Kettler, 2019; Thibaut et al., 2018). However, neither the first approach of selecting a limited number of individual discipline-based journals nor the second approach of selecting a specific focus for the review leads to an approach that provides a general overview of STEM education scholarship development based on existing journal publications.

\section{Current review}

Two issues were identified in setting the scope for this review.

1. What time period should be considered?

2. What publications will be selected for review?

\section{Time period}

We start with the easy one first. As discussed above, the acronym STEM did exist until the early 2000s. Although the existence of the acronym does not generate scholarship on student learning in STEM disciplines, it is symbolic and helps focus attention to efforts in STEM education. Since we want to examine the status and trends in STEM education, it is reasonable to start with the year 2000. Then, we can use the acronym of STEM as an identifier in locating specific research articles in a way as done by others (e.g., Brown, 2012; Mizell \& Brown, 2016). We chose the end of 2018 as the end of the time period for our review that began during 2019.

\section{Focusing on publications beyond individual discipline- based journals}

As mentioned before, scholars responded to the call for scholarship development in STEM education with publications that appeared in various outlets and diverse languages, including journals, books, and conference proceedings. However, journal publications are typically credited and valued as one of the most important outlets for research exchange (e.g., Erduran et al., 2015; Henderson et al., 2011; Lin et al., 2019; Xu et al., 2019). Thus, in this review, we will also focus on articles published in journals in English.

The discourse above on the complexity and ambiguity regarding STEM education suggests that scholars may publish their research in a wide range of journals beyond individual discipline-based journals. To search and select articles from a wide range of journals, we thought about the approach of searching selected databases with 
keywords as other scholars used in reviewing STEM education with a specific focus. However, existing journals in STEM education do not have a long history. In fact, IJ-STEM is the first journal in STEM education that has just been accepted into the Social Sciences Citation Index (SSCI) (Li, 2019a). Publications in many STEM education journals are practically not available in several important and popular databases, such as the Web of Science and Scopus. Moreover, some journals in STEM education were not normalized due to a journal's name change or irregular publication schedule. For example, the Journal of STEM Education was named as Journal of SMET Education when it started in 2000 in a print format, and the journal's name was not changed until 2003, Vol 4 (3 and 4), and also went fully on-line starting 2004 (Raju \& Sankar, 2003). A simple Google Scholar search with keywords will not be able to provide accurate information, unless you visit the journal's website to check all publications over the years. Those added complexities prevented us from taking the database search as a viable approach. Thus, we decided to identify journals first and then search and select articles from these journals. Further details about the approach are provided in the "Method" section.

\section{Research questions}

Given a broader range of journals and a longer period of time to be covered in this review, we can examine some of the same questions as the IJ-STEM review (Li, Froyd, \& Wang, 2019), but we do not have access to data on readership, articles accessed, or articles cited for the other journals selected for this review. Specifically, we are interested in addressing the following six research questions:

1. What were the status and trends in STEM education research from 2000 to the end of 2018 based on journal publications?

2. What were the patterns of publications in STEM education research across different journals?

3. Which countries or regions, based on the countries or regions in which authors were located, contributed to journal publications in STEM education?

4. What were the patterns of single-author and multiple-author publications in STEM education?

5. What main topics had emerged in STEM education research based on the journal publications?

6. What research methods did authors tend to use in conducting STEM education research?

\section{Method}

Based on the above discussion, we developed the methods for this literature review to follow careful sequential steps to identify journals first and then identify and select STEM education research articles published in these journals from January 2000 to the end of 2018. The methods should allow us to obtain a comprehensive overview about the status and trends of STEM education research based on a systematic analysis of related publications from a broad range of journals and over a longer period of time.

\section{Identifying journals}

We used the following three steps to search and identify journals for inclusion:

1. We assumed articles on research in STEM education have been published in journals that involve more than one traditional discipline. Thus, we used Google to search and identify all education journals with their titles containing either two, three, or all four disciplines of STEM. For example, we did Google search of all the different combinations of three areas of science, mathematics, technology ${ }^{1}$, and engineering as contained in a journal's title. In addition, we also searched possible journals containing the word STEAM in the title.

2. Since STEM education may be viewed as encompassing discipline-based education research, articles on STEM education research may have been published in traditional discipline-based education journals, such as the Journal of Research in Science Teaching. However, there are too many such journals. Yale's Poorvu Center for Teaching and Learning has listed 16 journals that publish articles spanning across undergraduate STEM education disciplines (see https://poorvucenter.yale. edu/FacultyResources/STEMjournals). Thus, we selected from the list some individual disciplinebased education research journals, and also added a few more common ones such as the Journal of Engineering Education.

3. Since articles on research in STEM education have appeared in some general education research journals, especially those well-established ones. Thus, we identified and selected a few of those journals that we noticed some publications in STEM education research.

Following the above three steps, we identified 45 journals (see Table 1).

\footnotetext{
${ }^{1}$ Journals containing the word "computers" or "ICT" appeared automatically when searching with the word "technology". Thus, the word of "computers" or "ICT" was taken as equivalent to "technology" if appeared in a journal's name.
} 
Table 1 A total of 45 selected journals and the top 36 with STEM education publications

\begin{tabular}{|c|c|c|c|c|}
\hline No. & Journal name & \# of subjects* & Start year & OA or not \\
\hline 1 & African Journal of Research in Mathematics, Science and Technology Education & 3 & 1997 & No \\
\hline 2 & American Educational Research Journal & 0 & 1964 & No \\
\hline 3 & British Journal of Educational Technology & 1 & 1970 & No \\
\hline 4 & Canadian Journal of Science, Mathematics and Technology Education & 3 & 2001 & No \\
\hline 5 & Computers \& Education & 1 & 1976 & No \\
\hline 6 & Educational Technology Research and Development & 1 & 1953 & No \\
\hline 7 & Eurasia Journal of Mathematics, Science and Technology Education & 3 & 2005 & Yes \\
\hline 8 & European Journal of Engineering Education & 1 & 1975 & No \\
\hline 9 & European Journal of STEM Education & 4 & 2016 & Yes \\
\hline 10 & International Journal of Cognitive Research in Science, Engineering and Education & 2 & 2013 & Yes \\
\hline 11 & International Journal of Education in Mathematics, Science, and Technology & 3 & 2013 & Yes \\
\hline 12 & International Journal of Engineering Education & 1 & 1985 & No \\
\hline 13 & International Journal of Innovation in Science \& Mathematics Education & 2 & 1997 & Yes \\
\hline 14 & International Journal of Mathematical Education in Science and Technology & 3 & 1970 & No \\
\hline 15 & International Journal of Science and Mathematics Education & 2 & 2003 & No \\
\hline 16 & International Journal of Science Education & 1 & 1979 & No \\
\hline 17 & International Journal of STEM Education & 4 & 2014 & Yes \\
\hline 18 & Journal for STEM Education Research & 4 & 2018 & No \\
\hline 19 & Journal of Computers in Mathematics and Science Teaching & 3 & 1981 & No \\
\hline 20 & Journal of Engineering Education & 1 & 1912 & No \\
\hline 21 & Journal of Pre-College Engineering Education Research & 1 & 2011 & Yes \\
\hline 22 & Journal of Professional Issues in Engineering Education and Practice & 1 & 1956 & No \\
\hline 23 & Journal of Research in Science Teaching & 1 & 1963 & No \\
\hline 24 & Journal of Research in STEM Education & 4 & 2015 & Yes \\
\hline 25 & Journal of Science Education and Technology & 2 & 1992 & No \\
\hline 26 & Journal of STEM Education & 4 & 2000 & Yes \\
\hline 27 & Journal of STEM Outreach & 4 & 2018 & Yes \\
\hline 28 & Journal of STEM Teacher Education & 4 & 1998 & Yes \\
\hline 29 & Journal of Technology and Science Education & 2 & 2011 & Yes \\
\hline 30 & Research in Science and Technological Education & 2 & 1983 & No \\
\hline 31 & School Science and Mathematics & 2 & 1901 & No \\
\hline 32 & Science Education & 1 & 1916 & No \\
\hline 33 & Technology, Pedagogy and Education & 1 & 1992 & No \\
\hline 34 & The Journal of Educational Research & 0 & 1920 & No \\
\hline 35 & The STEAM Journal & 5 & 2013 & No \\
\hline 36 & World Transactions on Engineering and Technology Education & 2 & 2002 & Yes \\
\hline \multicolumn{5}{|c|}{ (Journals listed below are those that did not have author self-identified STEM education publications) } \\
\hline 37 & Engineering Science and Education Journal (closed in 2002) & 2 & 1992 & No \\
\hline 38 & European Journal of Science and Mathematics Education & 2 & 2013 & Yes \\
\hline 39 & International Journal for Technology in Mathematics Education & 2 & 2004 & No \\
\hline 40 & International Journal of Technology and Engineering Education & 2 & 2004 & Yes \\
\hline 41 & Mathematics and Computer Education (closed in 2002) & 2 & 1967 & No \\
\hline 42 & Teaching Mathematics and Computer Science & 2 & 2003 & Yes \\
\hline 43 & Review of Science, Mathematics and ICT Education & 3 & 2007 & Yes \\
\hline 44 & Journal of STEAM Education (Non-English) & 5 & 2018 & No \\
\hline 45 & Science \& Education & 1 & 1992 & No \\
\hline
\end{tabular}

*\# of subjects refers to the number of disciplines in STEM that are included in a journal's name. For an education research journal without STEM discipline included, the value of " 0 " is assigned. For STEAM journals, the value of " 5 " is assigned 


\section{Identifying articles}

In this review, we will not discuss or define the meaning of STEM education. We used the acronym STEM (or STEAM, or written as the phrase of "science, technology, engineering, and mathematics") as a term in our search of publication titles and/or abstracts. To identify and select articles for review, we searched all items published in those 45 journals and selected only those articles that author(s) self-identified with the acronym STEM (or STEAM, or written as the phrase of "science, technology, engineering, and mathematics") in the title and/or abstract. We excluded publications in the sections of practices, letters to editors, corrections, and (guest) editorials. Our search found 798 publications that authors self-identified as in STEM education, identified from 36 journals. The remaining 9 journals either did not have publications that met our search terms or published in another language other than English (see the two separate lists in Table 1).

\section{Data analysis}

To address research question 3, we analyzed authorship to examine which countries/regions contributed to STEM education research over the years. Because each publication may have either one or multiple authors, we used two different methods to analyze authorship nationality that have been recognized as valuable from our review of IJ-STEM publications (Li, Froyd, \& Wang, 2019). The first method considers only the corresponding author's (or the first author, if no specific indication is given about the corresponding author) nationality and his/her first institution affiliation, if multiple institution affiliations are listed. Method 2 considers every author of a publication, using the following formula (Howard, Cole, \& Maxwell, 1987) to quantitatively assign and estimate each author's contribution to a publication (and thus associated institution's productivity), when multiple authors are included in a publication. As an example, each publication is given one credit point. For the publication co-authored by two, the first author would be given 0.6 and the second author 0.4 credit point. For an article contributed jointly by three authors, the three authors would be credited with scores of $0.47,0.32$, and 0.21 , respectively.

$$
\text { Credit Score }=\frac{\left(1.5^{n-i}\right)}{\sum_{i=1}^{n} 1.5^{i-1 .}}
$$

After calculating all the scores for each author of each paper, we added all the credit scores together in terms of each author's country/region. For brevity, we present only the top 10 countries/regions in terms of their total credit scores calculated using these two different methods, respectively.

To address research question 5, we used the same seven topic categories identified and used in our review of IJ-STEM publications (Li, Froyd, \& Wang, 2019). We tested coding 100 articles first to ensure the feasibility. Through test-coding and discussions, we found seven topic categories could be used to examine and classify all 798 items.

(1) K-12 teaching, teacher, and teacher education in STEM (including both pre-service and in-service teacher education)

(2) Post-secondary teacher and teaching in STEM (including faculty development, etc.)

(3) K-12 STEM learner, learning, and learning environment

(4) Post-secondary STEM learner, learning, and learning environments (excluding pre-service teacher education)

(5) Policy, curriculum, evaluation, and assessment in STEM (including literature review about a field in general)

(6) Culture and social and gender issues in STEM education

(7) History, epistemology, and perspectives about STEM and STEM education

To address research question 6, we coded all 798 publications in terms of (1) qualitative methods, (2) quantitative methods, (3) mixed methods, and (4) nonempirical studies (including theoretical or conceptual papers, and literature reviews). We assigned each publication to only one research topic and one method, following the process used in the IJ-STEM review ( $\mathrm{Li}$, Froyd, \& Wang, 2019). When there was more than one topic or method that could have been used for a publication, a decision was made in choosing and assigning a topic or a method. The agreement between two coders for all 798 publications was $89.5 \%$. When topic and method coding discrepancies occurred, a final decision was reached after discussion.

\section{Results and discussion}

In the following sections, we report findings as corresponding to each of the six research questions.

\section{The status and trends of journal publications in STEM education research from 2000 to 2018}

Figure 1 shows the number of publications per year. As Fig. 1 shows, the number of publications increased each year beginning in 2010. There are noticeable jumps from 2015 to 2016 and from 2017 to 2018 . The result shows that research in STEM education had grown significantly since 2010, and the most recent large number of STEM education publications also suggests that STEM education research gained its own recognition by many different journals for publication as a hot and important topic area. 


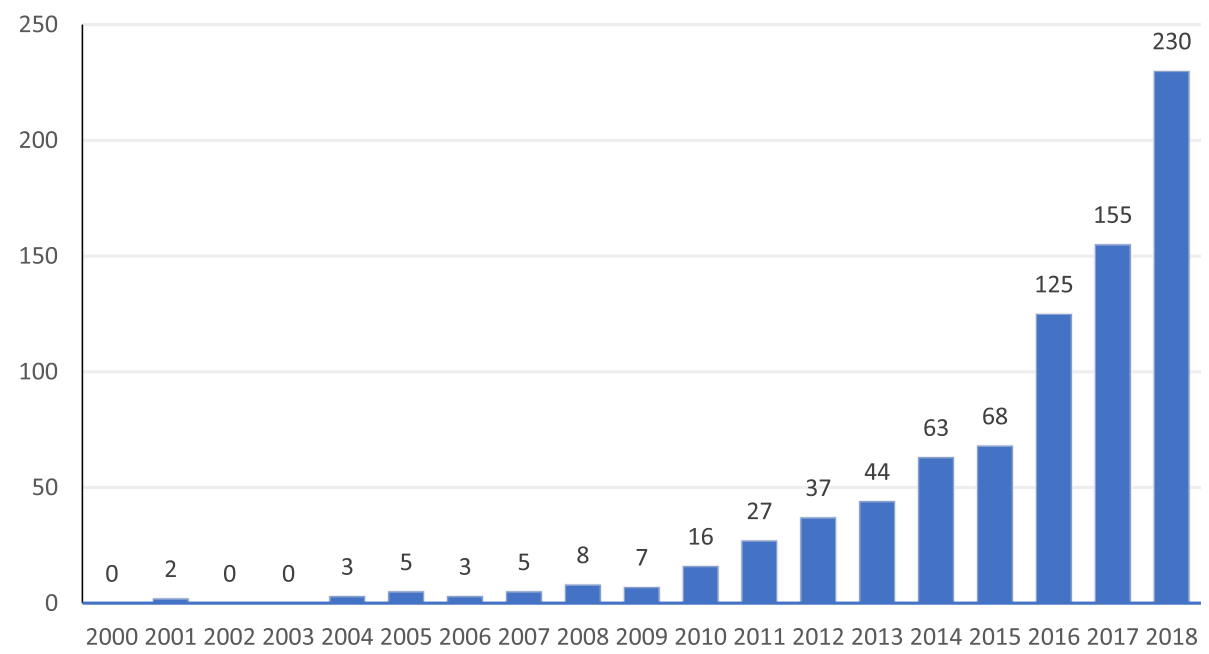

Fig. 1 The distribution of STEM education publications over the years

Among the 798 articles, there were 549 articles with the word "STEM" (or STEAM, or written with the phrase of "science, technology, engineering, and mathematics") included in the article's title or both title and abstract and 249 articles without such identifiers included in the title but abstract only. The results suggest that many scholars tended to include STEM in the publications' titles to highlight their research in or about STEM education. Figure 2 shows the number of publications per year where publications are distinguished depending on whether they used the term STEM in the title or only in the abstract. The number of publications in both categories had significant increases since 2010. Use of the acronym STEM in the title was growing at a faster rate than using the acronym only in the abstract.

Not all the publications that used the acronym STEM in the title and/or abstract reported on a study involving all four STEM areas. For each publication, we further examined the number of the four areas involved in the reported study.

Figure 3 presents the number of publications categorized by the number of the four areas involved in the study, breaking down the distribution of these 798 publications in terms of the content scope being focused on. Studies involving all four STEM areas are the most numerous with $488(61.2 \%)$ publications, followed by involving one area (141, 17.7\%), then studies involving both STEM and non-STEM $(84,10.5 \%)$, and finally studies involving two or three areas of STEM $(72,9 \% ; 13,1.6 \%$; respectively). Publications that used the acronym STEAM in either the title or abstract were classified as involving both STEM and non-STEM. For example, both of the following publications were included in this category.

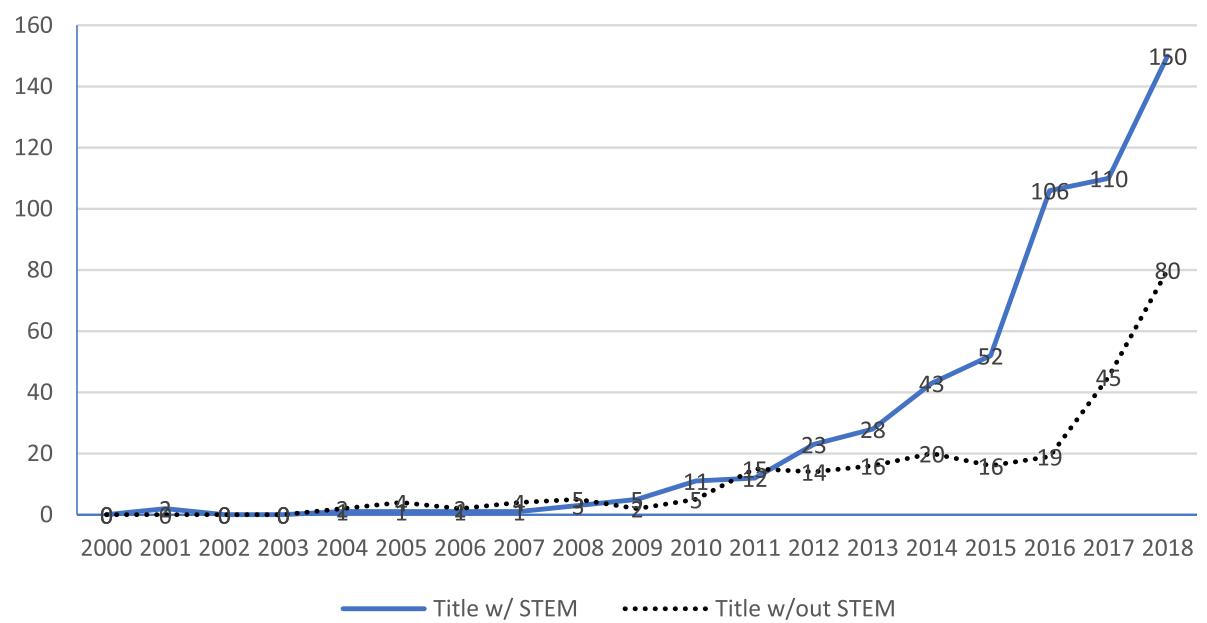

Fig. 2 The trends of STEM education publications with vs. without STEM included in the title 


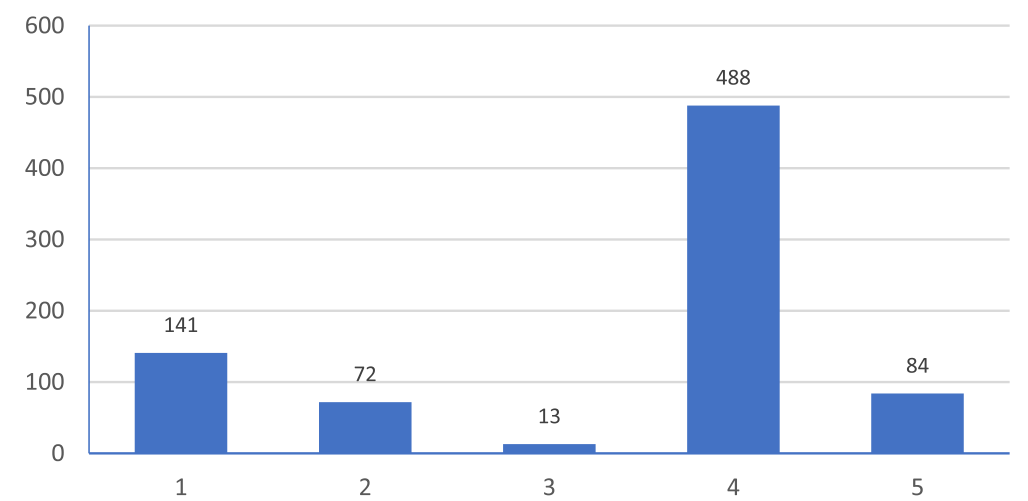

Fig. 3 Publication distribution in terms of content scope being focused on. (Note: 1=single subject of STEM, 2=two subjects of STEM, $3=$ three subjects of STEM, 4=four subjects of STEM, 5=topics related to both STEM and non-STEM)

Dika and D'Amico (2016). "Early experiences and integration in the persistence of first-generation college students in STEM and non-STEM majors." Journal of Research in Science Teaching, 53(3), 368-383. (Note: this article focused on early experience in both STEM and Non-STEM majors.)

Sochacka, Guyotte, and Walther (2016). "Learning together: A collaborative autoethnographic exploration of STEAM (STEM+ the Arts) education." Journal of Engineering Education, 105(1), 15-42. (Note: this article focused on STEAM (both STEM and Arts).)

Figure 4 presents the number of publications per year in each of the five categories described earlier (category 1, one area of STEM; category 2, two areas of STEM; category 3, three areas of STEM; category 4, four areas of STEM; category 5, STEM and non-STEM). The category that had grown most rapidly since 2010 is the one involving all four areas. Recent growth in the number of publications in category 1 likely reflected growing interest of traditional individual disciplinary based educators in developing and sharing multidisciplinary and interdisciplinary scholarship in STEM education, as what was noted recently by Li and Schoenfeld (2019) with publications in IJ-STEM.

\section{Patterns of publications across different journals}

Among the 36 journals that published STEM education articles, two are general education research journals (referred to as "subject-0"), 12 with their titles containing one discipline of STEM ("subject-1"), eight with journal's titles covering two disciplines of STEM ("subject-2"), six covering three disciplines of STEM ("subject-3"), seven containing the word STEM ("subject-4"), and one in STEAM education ("subject-5").

Table 2 shows that both subject- 0 and subject- 1 journals were usually mature journals with a long history, and they were all traditional subscription-based journals, except the Journal of Pre-College Engineering Education Research, a subject-1 journal established in 2011 that provided open access (OA). In comparison to subject- 0 and subject- 1 journals, subject- 2 and subject- 3 journals were relatively newer but still had quite many years of

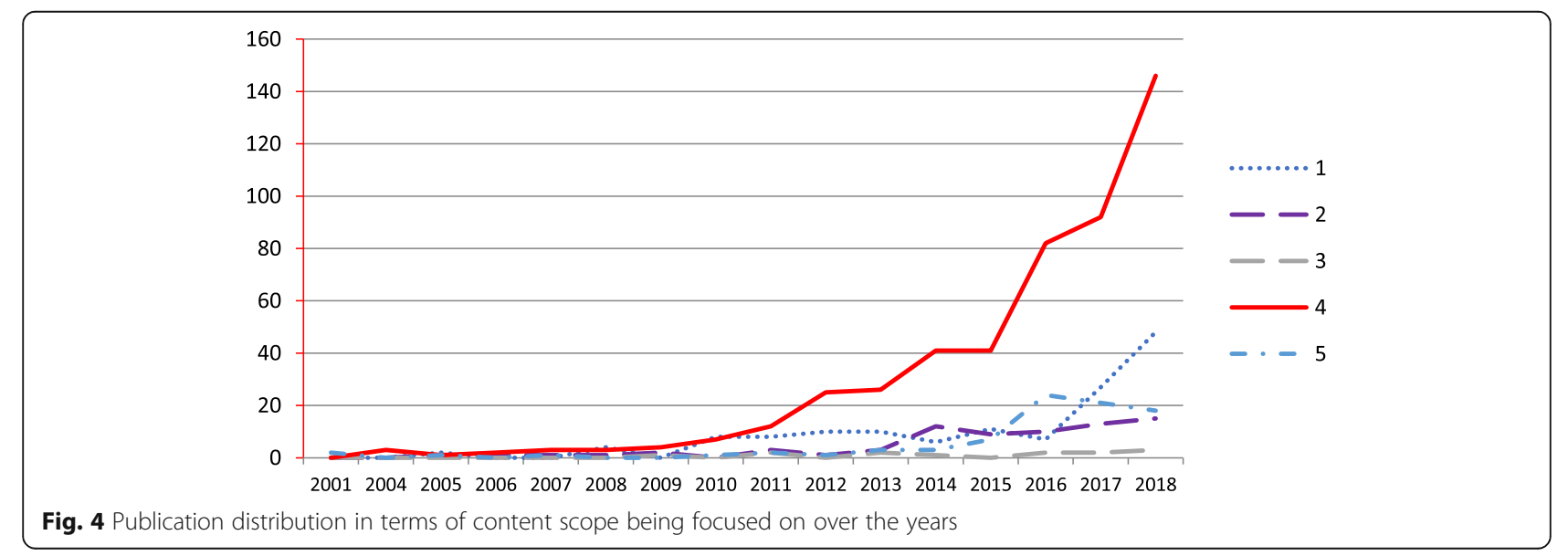


Table $\mathbf{2}$ Information about journals in different subject categories

\begin{tabular}{lllll}
\hline \# of subjects & \# of journals & \# of OA journals & Years of history (on average) & \# of STEM articles (\%) \\
\hline Subject-0 & 2 & 0 & 77 & $36(4.5 \%)$ \\
Subject-1 & 12 & 1 & 53.3 & $259(32.5 \%)$ \\
Subject-2 & 8 & 4 & 31.3 & $185(23.2 \%)$ \\
Subject-3 & 6 & 2 & 24.5 & $92(11.5 \%)$ \\
Subject-4 & 7 & 6 & 7.7 & $205(25.7 \%)$ \\
Subject-5 & 1 & 0 & 6 & $21(2.6 \%)$
\end{tabular}

*Calculation based on each journal's inaugural year to 2018 (included)

history on average. There are also some more journals in these two categories that provided OA. Subject- 4 and subject- 5 journals had a short history, and most provided OA. The results show that well-established journals had tended to focus on individual disciplines or education research in general. Multidisciplinary and interdisciplinary education journals were started some years later, followed by the recent establishment of several STEM or STEAM journals.

Table 2 also shows that subject-1, subject-2, and subject- 4 journals published approximately a quarter each of the publications. The number of publications in subject-1 journals is interested, because we selected a relatively limited number of journals in this category. There are many other journals in the subject- 1 category (as well as subject-0 journals) that we did not select, and thus it is very likely that we did not include some STEM education articles published in subject- 0 or subject- 1 journals that we did not include in our study.

Figure 5 shows the number of publications per year in each of the five categories described earlier (subject- 0 through subject-5). The number of publications per year in subject- 5 and subject- 0 journals did not change much over the time period of the study. On the other hand, the number of publications per year in subject-4 (all 4 areas), subject-1 (single area), and subject-2 journals were all over 40 by the end of the study period. The number of publications per year in subject- 3 journals increased but remained less than 30. At first sight, it may be a bit surprising that the number of publications in STEM education per year in subject- 1 journals increased much faster than those in subject-2 journals over the past few years. However, as Table 2 indicates these journals had long been established with great reputations, and scholars would like to publish their research in such journals. In contrast to the trend in subject- 1 journals, the trend in subject- 4 journals suggests that STEM education journals collectively started to gain its own identity for publishing and sharing STEM education research.

Figure 6 shows the number of STEM education publications in each journal where the bars are color-coded (yellow, subject-0; light blue, subject-1; green, subject-2; purple, subject-3; dark blue, subject-4; and black, subject-5). There is no clear pattern shown in terms of the overall number of STEM education publications across categories or journals, but very much individual journal-based performance. The result indicates that the number of STEM education publications might heavily rely on the individual journal's willingness and capability

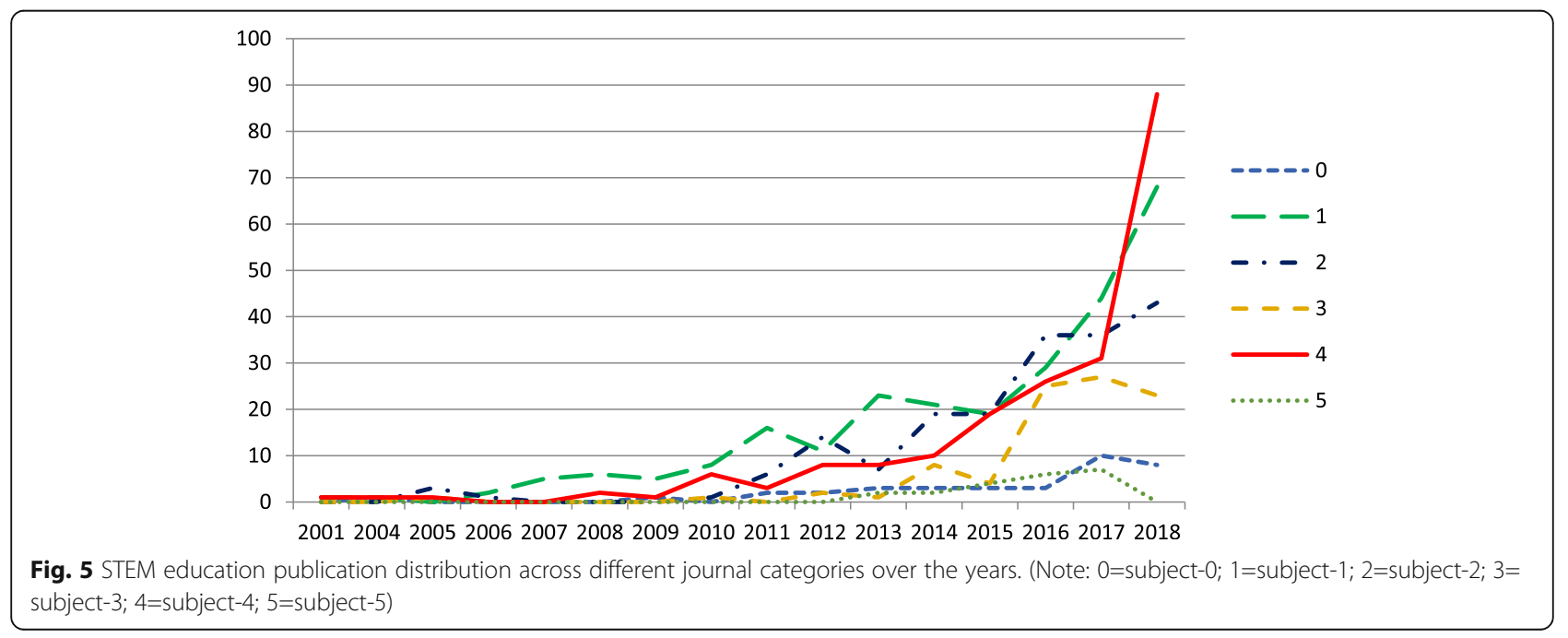




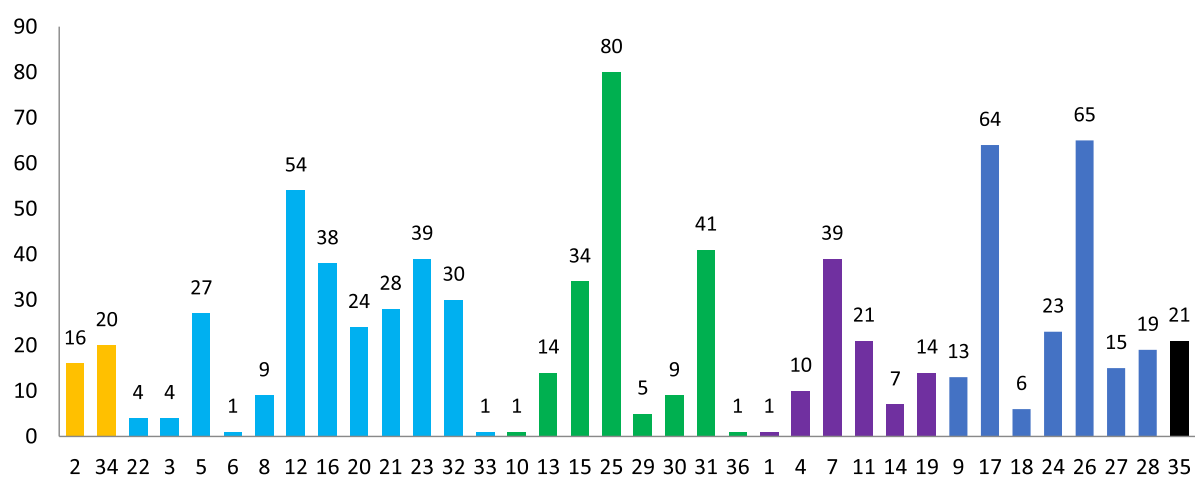

Fig. 6 Publication distribution across all 36 individual journals across different categories with the same color-coded for journals in the same subject category

of attracting STEM education research work and thus suggests the potential value of examining individual journal's performance.

The top five journals in terms of the number of STEM education publications are Journal of Science Education and Technology (80 publications, journal number 25 in Fig. 6), Journal of STEM Education (65 publications, journal number 26), International Journal of STEM Education (64 publications, journal number 17), International Journal of Engineering Education (54 publications, journal number 12), and School Science and Mathematics (41 publications, journal number 31). Among these five journals, two journals are specifically on STEM education (J26, J17), two on two subjects of STEM (J25, J31), and one on one subject of STEM (J12).

Figure 7 shows the number of STEM education publications per year in each of these top five journals. As expected, based on earlier trends, the number of publications per year increased over the study period. The largest increase was in the International Journal of STEM Education (J17) that was established in 2014. As the other four journals were all established in or before
2000, J17's short history further suggests its outstanding performance in attracting and publishing STEM education articles since 2014 (Li, 2018b; Li, Froyd, \& Wang, 2019). The increase was consistent with the journal's recognition as the first STEM education journal for inclusion in SSCI starting in 2019 (Li, 2019a).

\section{Top 10 countries/regions where scholars contributed journal publications in STEM education}

Table 3 shows top countries/regions in terms of the number of publications, where the country/region was established by the authorship using the two different methods presented above. About $75 \%$ (depending on the method) of contributions were made by authors from the USA, followed by Australia, Canada, Taiwan, and UK. Only Africa as a continent was not represented among the top 10 countries/regions. The results are relatively consistent with patterns reported in the IJSTEM study (Li, Froyd, \& Wang, 2019)

Further examination of Table 3 reveals that the two methods provide not only fairly consistent results but also yield some differences. For example, Israel and

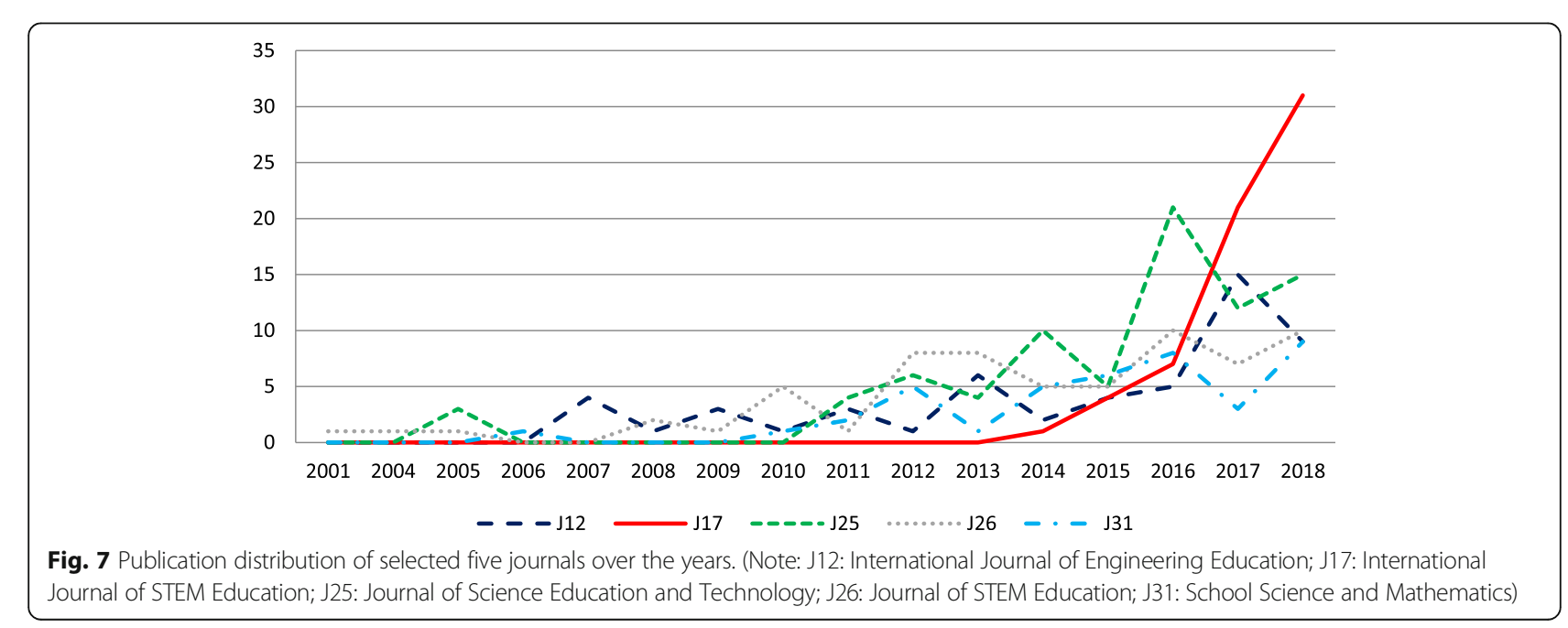


Table 3 Top 10 authorship countries/regions for all 798 publications (2000-2018) using the two methods

\begin{tabular}{|c|c|c|c|c|c|}
\hline \multirow[t]{2}{*}{ Rank } & \multicolumn{2}{|l|}{ Method $1^{a}$} & \multirow[t]{2}{*}{ Rank } & \multicolumn{2}{|l|}{ Method 2} \\
\hline & Country & Score (\%) & & Country & Scores (\%) \\
\hline 1 & USA & $603(75.75 \%)$ & 1 & USA & $596.28(74.91 \%)$ \\
\hline 2 & Australia & $37(4.65 \%)$ & 2 & Australia & $38.29(4.81 \%)$ \\
\hline 3 & Canada & 18 (2.26\%) & 3 & Canada & $18.42(2.31 \%)$ \\
\hline 4 & Taiwan & 14 (1.76\%) & 4 & Taiwan & $13.76(1.73 \%)$ \\
\hline 4 & UK & 14 (1.76\%) & 5 & UK & $12.83(1.61 \%)$ \\
\hline 6 & Spain & $12(1.51 \%)$ & 6 & Spain & 12.53 (1.57\%) \\
\hline 7 & Israel & $9(1.13 \%)$ & 7 & South Korea & 9.55 (1.20\%) \\
\hline 7 & South Korea & $9(1.13 \%)$ & 8 & Turkey & $9.02(1.13 \%)$ \\
\hline 9 & Germany & $8(1.01 \%)$ & 9 & Israel & $8.68(1.09 \%)$ \\
\hline 9 & Netherlands & $8(1.01 \%)$ & 10 & Netherlands & 7.69 (0.97\%) \\
\hline 9 & Turkey & $8(1.01 \%)$ & & & \\
\hline
\end{tabular}

${ }^{a}$ Method 1 refers to the method where only the corresponding author (or the first author, if no specific indication was provided about the corresponding author) was credited, whereas method 2 refers to the case when all co-authors were credited. The same notations are used in Tables 4 and 5

Germany had more publication credit if only the corresponding author was considered, but South Korea and Turkey had more publication credit when co-authors were considered. The results in Table 3 show that each method has value when analyzing and comparing publications by country/region or institution based on authorship.

Recognizing that, as shown in Fig. 1, the number of publications per year increased rapidly since 2010, Table 4 shows the number of publications by country/ region over a 10-year period (2009-2018) and Table 5 shows the number of publications by country/region over a 5-year period (2014-2018). The ranks in Tables 3, 4 , and 5 are fairly consistent, but that would be expected since the larger numbers of publications in STEM education had occurred in recent years. At the same time, it

Table 4 Top 10 authorship countries/regions for 772 publications (2009-2018) using the two methods

\begin{tabular}{lllllll}
\hline Rank & Method 1 & \multicolumn{3}{l}{ Rank } & & Method 2 \\
\cline { 2 - 3 } & Country & Score (\%) & & Country & Scores (\%) \\
\hline 1 & USA & $580(75.13 \%)$ & 1 & USA & $573.04(74.23 \%)$ \\
2 & Australia & $37(4.79 \%)$ & 2 & Australia & $37.89(4.91 \%)$ \\
3 & Canada & $18(2.33 \%)$ & 3 & Canada & $18.42(2.39 \%)$ \\
4 & Taiwan & $14(1.81 \%)$ & 4 & Taiwan & $13.76(1.78 \%)$ \\
4 & UK & $14(1.81 \%)$ & 5 & UK & $12.83(1.66 \%)$ \\
6 & Spain & $12(1.55 \%)$ & 6 & Spain & $12.53(1.62 \%)$ \\
7 & South Korea & $9(1.17 \%)$ & 7 & South Korea & $9.55(1.24 \%)$ \\
8 & Germany & $8(1.04 \%)$ & 8 & Turkey & $9.02(1.17 \%)$ \\
8 & Israel & $8(1.04 \%)$ & 9 & Israel & $8(1.04 \%)$ \\
8 & Netherlands & $8(1.04 \%)$ & 10 & Netherlands & $7.69(1.00 \%)$ \\
8 & Turkey & $8(1.04 \%)$ & & & \\
\hline
\end{tabular}

Table 5 Top 10 authorship countries/regions for 641 publications (2014-2018) using the two methods

\begin{tabular}{|c|c|c|c|c|c|}
\hline \multirow[t]{2}{*}{ Rank } & \multicolumn{2}{|l|}{ Method 1} & \multirow[t]{2}{*}{ Rank } & \multicolumn{2}{|l|}{ Method 2} \\
\hline & Country & Score (\%) & & Country & Scores (\%) \\
\hline 1 & USA & $473(73.79 \%)$ & 1 & USA & 466.78 (72.82\%) \\
\hline 2 & Australia & $30(4.68 \%)$ & 2 & Australia & $30.89(4.82 \%)$ \\
\hline 3 & Canada & $17(2.65 \%)$ & 3 & Canada & 17.82 (2.78\%) \\
\hline 4 & UK & $13(2.03 \%)$ & 4 & Spain & $12.53(1.95 \%)$ \\
\hline 5 & Spain & $12(1.87 \%)$ & 5 & UK & 11.99 (1.87\%) \\
\hline 6 & Taiwan & 11 (1.72\%) & 6 & Taiwan & $10.71(1.67 \%)$ \\
\hline 7 & South Korea & $9(1.40 \%)$ & 7 & South Korea & 9.15 (1.43\%) \\
\hline 8 & Turkey & $8(1.25 \%)$ & 8 & Turkey & $9.02(1.41 \%)$ \\
\hline 9 & Germany & $7(1.09 \%)$ & 9 & Germany & 6.89 (1.07\%) \\
\hline 9 & Malaysia & $7(1.09 \%)$ & 10 & Malaysia & $6.68(1.04 \%)$ \\
\hline 9 & Netherlands & 7 (1.09\%) & & & \\
\hline
\end{tabular}

is interesting to note in Table 5 some changes over the recent several years with Malaysia, but not Israel, entering the top 10 list when either method was used to calculate author's credit.

\section{Patterns of single-author and multiple-author publications in STEM education}

Since STEM education differs from traditional individual disciplinary education, we are interested in determining how common joint co-authorship with collaborations was in STEM education articles. Figure 8 shows that joint co-authorship was very common among these 798 STEM education publications, with $83.7 \%$ publications with two or more co-authors. Publications with two, three, or at least five co-authors were highest, with 204, 181, and 157 publications, respectively.

Figure 9 shows the number of publications per year using the joint authorship categories in Fig. 8. Each category shows an increase consistent with the increase shown in Fig. 1 for all 798 publications. By the end of the time period, the number of publications with two, three, or at least five co-authors was the largest, which might suggest an increase in collaborations in STEM education research.

Co-authors can be from the same or different countries/ regions. Figure 10 shows the number of publications per year by single authors (no collaboration), co-authors from the same country (collaboration in a country/region), and co-authors from different countries (collaboration across countries/regions). Each year the largest number of publications was by co-authors from the same country, and the number increased dramatically during the period of the study. Although the number of publications in the other two categories increased, the numbers of publications were noticeably fewer than the number of publications by co-authors from the same country. 


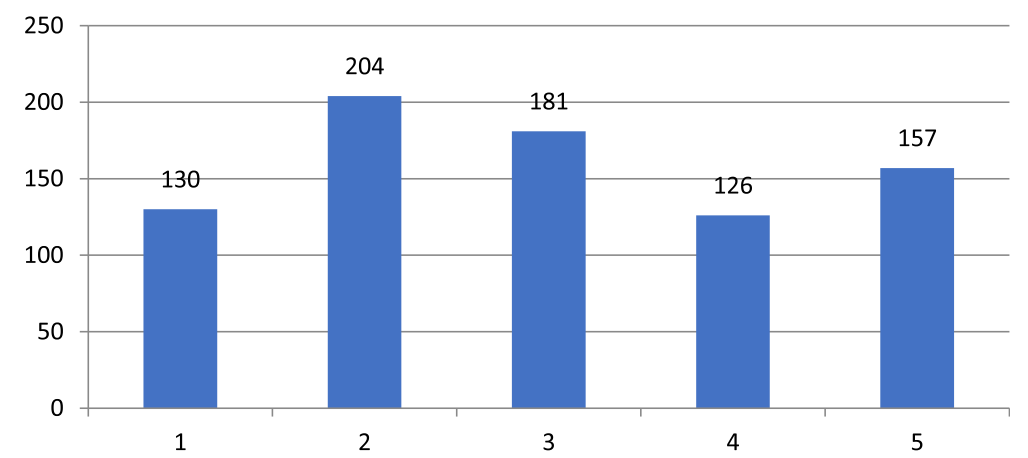

Fig. 8 Number of publications with single or different joint authorship. (Note: 1=single author; $2=$ two co-authors; $3=$ three co-authors; $4=$ four coauthors; $5=$ five or more co-authors)

\section{Published articles by research topics}

Figure 11 shows the number of publications in each of the seven topic categories. The topic category of goals, policy, curriculum, evaluation, and assessment had almost half of publications $(375,47 \%)$. Literature reviews were included in this topic category, as providing an overview assessment of education and research development in a topic area or a field. Sample publications included in this category are listed as follows:

DeCoito (2016). "STEM education in Canada: A knowledge synthesis." Canadian Journal of Science, Mathematics and Technology Education, 16(2), 114128. (Note: this article provides a national overview of STEM initiatives and programs, including success, criteria for effective programs and current research in STEM education.)

Ring-Whalen, Dare, Roehrig, Titu, and Crotty (2018). "From conception to curricula: The role of science, technology, engineering, and mathematics in integrated STEM units." International Journal of Education in Mathematics Science and Technology, 6(4), 343-362. (Note: this article investigates the conceptions of integrated STEM education held by in-service science teachers through the use of photo-elicitation interviews and examines how those conceptions were reflected in teacher-created integrated STEM curricula.)

Schwab et al. (2018). "A summer STEM outreach program run by graduate students: Successes, challenges, and recommendations for implementation." Journal of Research in STEM Education, 4(2), 117-129. (Note: the article details the organization and scope of the Foundation in Science and Mathematics Program and evaluates this program.)

The topic with the second most publications was "K12 teaching, teacher and teacher education" (103,

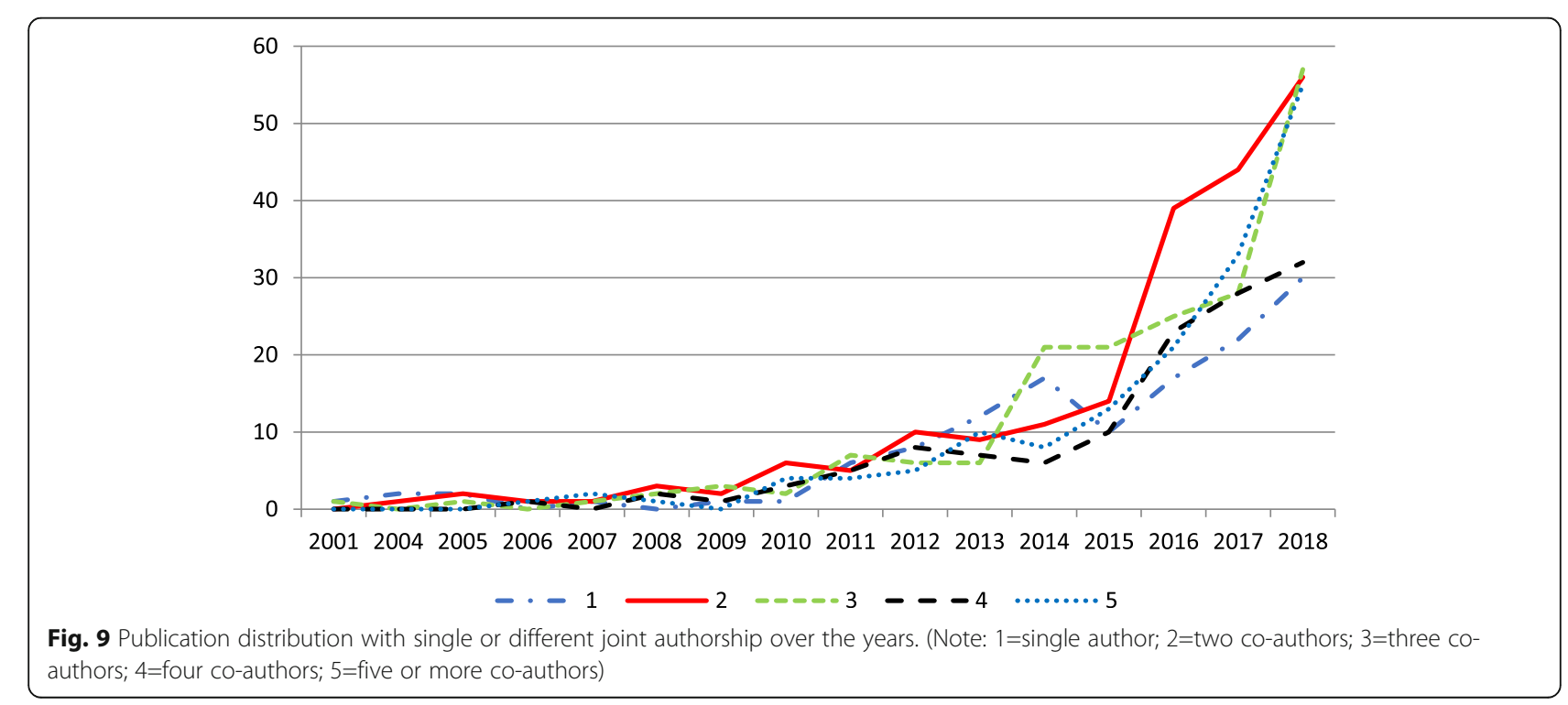




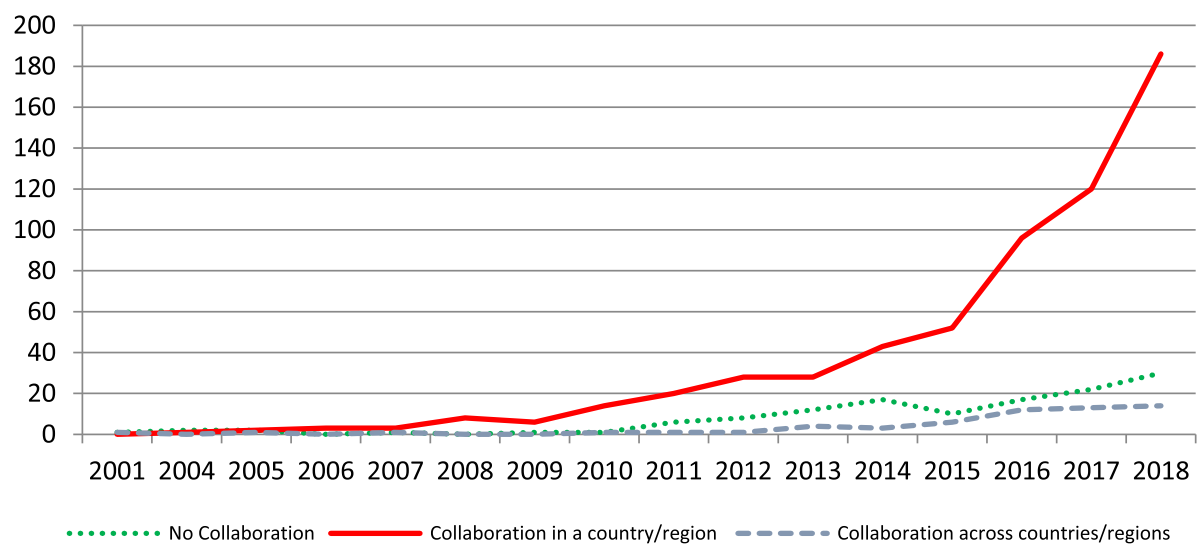

Fig. 10 Publication distribution in authorship across different categories in terms of collaboration over the years

$12.9 \%)$, followed closely by " $\mathrm{K}-12$ learner, learning, and learning environment" (97, 12.2\%). The results likely suggest the research community had a broad interest in both teaching and learning in K-12 STEM education. The top three topics were the same in the IJ-STEM review (Li, Froyd, \& Wang, 2019).

Figure 11 also shows there was a virtual tie between two topics with the fourth most cumulative publications, "post-secondary STEM learner \& learning" (76, 9.5\%) and "culture, social, and gender issues in STEM" (78, 9.8\%), such as STEM identity, students' career choices in STEM, and inclusion. This result is different from the IJSTEM review (Li, Froyd, \& Wang, 2019), where "postsecondary STEM teacher \& teaching" and "post-secondary STEM learner \& learning" were tied as the fourth most common topics. This difference is likely due to the scope of journals and the length of the time period being reviewed.
Figure 12 shows the number of publications per year in each topic category. As expected from the results in Fig. 11 the number of publications in topic category 5 (goals, policy, curriculum, evaluation, and assessment) was the largest each year. The numbers of publications in topic category 3 (K-12 learner, learning, and learning environment), 1 (K-12 teaching, teacher, and teacher education), 6 (culture, social, and gender issues in STEM), and 4 (post-secondary STEM learner and learning) were also increasing. Although Fig. 11 shows the number of publications in topic category 1 was slightly more than the number of publications in topic category 3 (see Fig. 11), the number of publications in topic category 3 was increasing more rapidly in recent years than its counterpart in topic category 1 . This may suggest a more rapidly growing interest in K-12 STEM learner, learning, and learning environment. The numbers of publications in topic categories 2 and 7 were not

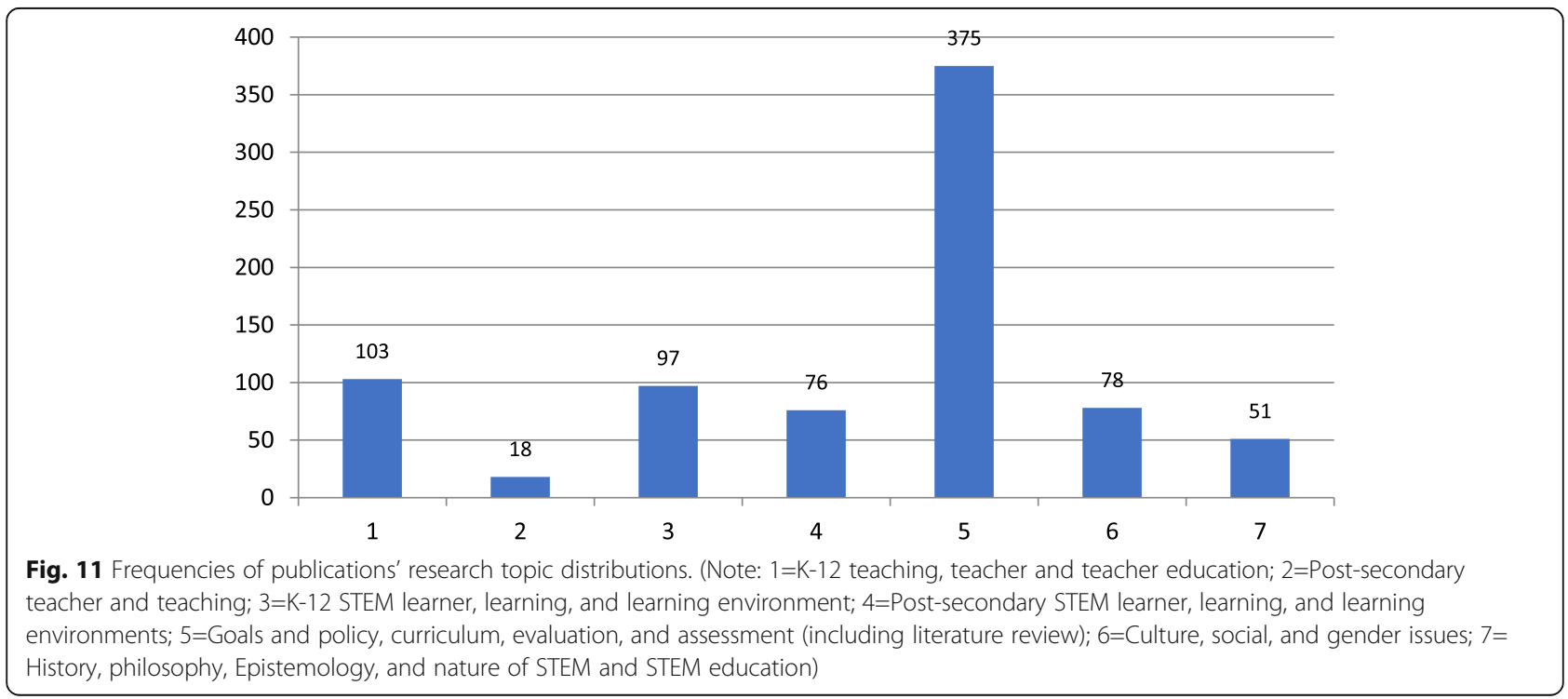




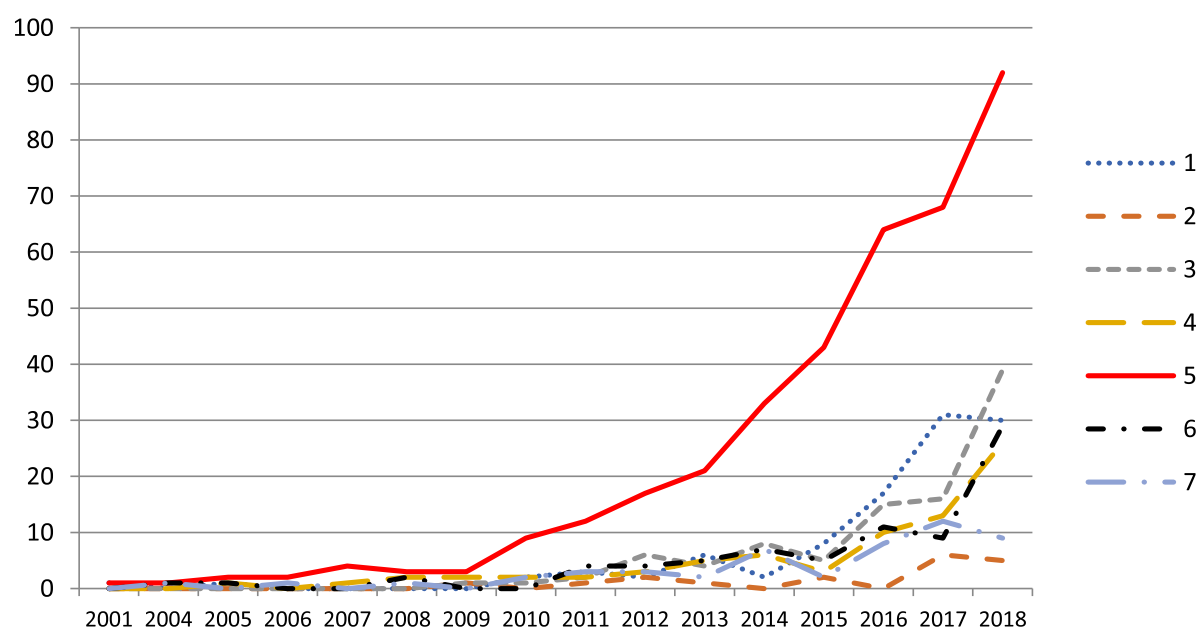

Fig. 12 Publication distributions in terms of research topics over the years

increasing, but the number of publications in IJ-STEM in topic category 2 was notable (Li, Froyd, \& Wang, 2019). It will be interesting to follow trends in the seven topic categories in the future.

\section{Published articles by research methods}

Figure 13 shows the number of publications per year by research methods in empirical studies. Publications with non-empirical studies are shown in a separate category. Although the number of publications in each of the four categories increased during the study period, there were many more publications presenting empirical studies than those without. For those with empirical studies, the number of publications using quantitative methods increased most rapidly in recent years, followed by qualitative and then mixed methods. Although there were quite many publications with non-empirical studies (e.g., theoretical or conceptual papers, literature reviews) during the study period, the increase of the number of publications in this category was noticeably less than empirical studies.

\section{Concluding remarks}

The systematic analysis of publications that were considered to be in STEM education in 36 selected journals shows tremendous growth in scholarship in this field from 2000 to 2018, especially over the past 10 years. Our analysis indicates that STEM education research has been increasingly recognized as an important topic area and studies were being published across many different journals. Scholars still hold diverse perspectives about how research is designated as STEM education; however, authors have been increasingly distinguishing their articles with STEM, STEAM, or related words in the titles, abstracts, and lists of keywords during the past 10 years. Moreover, our systematic analysis shows a dramatic

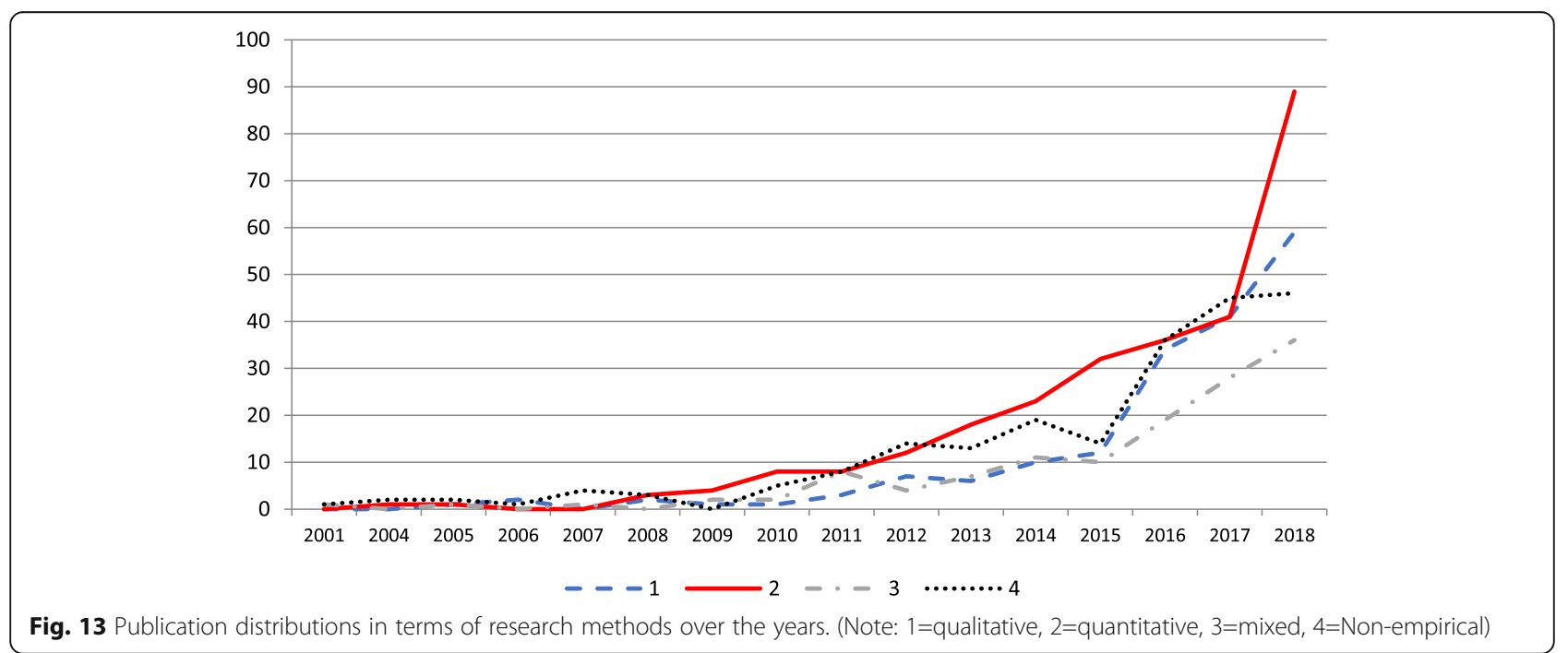


increase in the number of publications in STEM education journals in recent years, which indicates that these journals have been collectively developing their own professional identity. In addition, the International Journal of STEM Education has become the first STEM education journal to be accepted in SSCI in 2019 (Li, 2019a). The achievement may mark an important milestone as STEM education journals develop their own identity for publishing and sharing STEM education research.

Consistent with our previous reviews (Li, Froyd, \& Wang, 2019; Li, Wang, \& Xiao, 2019), the vast majority of publications in STEM education research were contributed by authors from the USA, where STEM and STEAM education originated, followed by Australia, Canada, and Taiwan. At the same time, authors in some countries/regions in Asia were becoming very active in the field over the past several years. This trend is consistent with findings from the IJ-STEM review (Li, Froyd, \& Wang, 2019). We certainly hope that STEM education scholarship continues its development across all five continents to support educational initiatives and programs in STEM worldwide.

Our analysis has shown that collaboration, as indicated by publications with multiple authors, has been very common among STEM education scholars, as that is often how STEM education distinguishes itself from the traditional individual disciplinary based education. Currently, most collaborations occurred among authors from the same country/region, although collaborations across cross-countries/regions were slowly increasing.

With the rapid changes in STEM education internationally ( $\mathrm{Li}, 2019 \mathrm{~b})$, it is often difficult for researchers to get an overall sense about possible hot topics in STEM education especially when STEM education publications appeared in a vast array of journals across different fields. Our systematic analysis of publications has shown that studies in the topic category of goals, policy, curriculum, evaluation, and assessment have been the most prevalent, by far. Our analysis also suggests that the research community had a broad interest in both teaching and learning in K-12 STEM education. These top three topic categories are the same as in the IJ-STEM review (Li, Froyd, \& Wang, 2019). Work in STEM education will continue to evolve and it will be interesting to review the trends in another 5 years.

Encouraged by our recent IJ-STEM review, we began this review with an ambitious goal to provide an overview of the status and trends of STEM education research. In a way, this systematic review allowed us to achieve our initial goal with a larger scope of journal selection over a much longer period of publication time. At the same time, there are still limitations, such as the decision to limit the number of journals from which we would identify publications for analysis. We understand that there are many publications on STEM education research that were not included in our review. Also, we only identified publications in journals. Although this is one of the most important outlets for scholars to share their research work, future reviews could examine publications on STEM education research in other venues such as books, conference proceedings, and grant proposals.

\section{Abbreviations}

ICT: Information and Communications Technology; IJ-STEM: International Journal of STEM Education; K-12: Kindergarten-Grade 12; SMET: Science, Mathematics, Engineering, and Technology; STEAM: Science, Technology, Engineering, Arts, and Mathematics; STEM: Science, Technology, Engineering, and Mathematics

\section{Authors' contributions}

YL conceptualized the study and drafted the manuscript. KW and YX contributed with data collection, coding, and analyses. JEF reviewed drafts and contributed to manuscript revisions. All authors read and approved the final manuscript.

Funding

Not applicable

\section{Availability of data and materials}

The data and materials used and analyzed for the report are publicly available at the various journal websites.

\section{Competing interests}

The authors declare that they have no competing interests.

\section{Author details}

${ }^{1}$ Texas A\&M University, College Station, TX 77843-4232, USA. ${ }^{2}$ Nicholls State University, Thibodaux, LA 70310, USA. ${ }^{3}$ Ohio State University, Columbus, OH 43210, USA.

Received: 10 February 2020 Accepted: 12 February 2020

Published online: 10 March 2020

\section{References}

Borrego, M., Foster, M. J., \& Froyd, J. E. (2015). What is the state of the art of systematic review in engineering education? Journal of Engineering Education, 104(2), 212-242. https://doi.org/10.1002/jee.20069.

Bray, A., \& Tangney, B. (2017). Technology usage in mathematics education research - a systematic review of recent trends. Computers \& Education, 114, 255-273.

Brown, J. (2012). The current status of STEM education research. Journal of STEM Education: Innovations \& Research, 13(5), 7-11.

Christenson, J. (2011). Ramaley coined STEM term now used nationwide. Winona Daily News Retrieved from http://www.winonadailynews.com/news/local/article_45 7afe3e-0db3-11e1-abe0-001cc4c03286.html Accessed on 16 Jan 2018.

Chute, E. (2009). STEM education is branching out. Pittsburgh Post-Gazette Feb 9, 2009. https://www.post-gazette.com/news/education/2009/02/10/STEMeducation-is-branching-out/stories/200902100165 Accessed on 2 Jan 2020.

DeCoito, I. (2016). STEM education in Canada: A knowledge synthesis. Canadian Journal of Science, Mathematics and Technology Education, 16(2), 114-128.

Dika, S. L., \& D'Amico, M. M. (2016). Early experiences and integration in the persistence of first-generation college students in STEM and non-STEM majors. Journal of Research in Science Teaching, 53(3), 368-383.

English, L. D. (2016). STEM education K-12: Perspectives on integration. International Journal of STEM Education, 3, 3. https://doi.org/10.1186/s4059 4-016-0036-1.

Erduran, S., Ozdem, Y., \& Park, J.-Y. (2015). Research trends on argumentation in science education: A journal content analysis from 1998-2014. International Journal of STEM Education, 2, 5. https://doi.org/10.1186/s40594-015-0020-1. 
Gonzalez, H. B. \& Kuenzi, J. J. (2012). Science, technology, engineering, and mathematics (STEM) education: A primer. CRS report for congress, R42642, https://fas.org/sgp/crs/misc/R42642.pdf Accessed on 2 Jan 2020.

Henderson, C., Beach, A., \& Finkelstein, N. (2011). Facilitating change in undergraduate STEM instructional practices: An analytic review of the literature. Journal of Research in Science Teaching, 48(8), 952-984.

Honey, M., Pearson, G., \& Schweingruber, A. (2014). STEM integration in K-12 education: Status, prospects, and an agenda for research. Washington: National Academies Press.

Howard, G. S., Cole, D. A., \& Maxwell, S. E. (1987). Research productivity in psychology based on publication in the journals of the American Psychological Association. American Psychologist, 42(11), 975-986.

Johnson, C. C., Peters-Burton, E. E., \& Moore, T. J. (2015). STEM roadmap: A framework for integration. London: Taylor \& Francis.

Kelley, T. R., \& Knowles, J. G. (2016). A conceptual framework for integrated STEM education. International Journal of STEM Education, 3, 11. https://doi.org/10. 1186/s40594-016-0046-z.

Kilpatrick, J. (1992). A history of research in mathematics education. In D. A. Grouws (Ed.), Handbook of research on mathematics teaching and learning (pp. 3-38). New York: Macmillan.

Kim, A. Y., Sinatra, G. M., \& Seyranian, V. (2018). Developing a STEM identity among young women: A social identity perspective. Review of Educational Research, 88(4), 589-625.

Li, Y. (2014). International journal of STEM education - a platform to promote STEM education and research worldwide. International Journal of STEM Education, 1, 1. https://doi.org/10.1186/2196-7822-1-1.

Li, Y. (2018a). Journal for STEM education research - promoting the development of interdisciplinary research in STEM education. Journal for STEM Education Research, 1(1-2), 1-6. https://doi.org/10.1007/s41979-018-0009-z.

$\mathrm{Li}, \mathrm{Y}$. (2018b). Four years of development as a gathering place for international researchers and readers in STEM education. International Journal of STEM Education, 5, 54. https://doi.org/10.1186/s40594-018-0153-0.

Li, Y. (2019a). Five years of development in pursuing excellence in quality and global impact to become the first journal in STEM education covered in SSCl. International Journal of STEM Education, 6, 42. https://doi.org/10.1186/s40594-019-0198-8.

Li, Y. (2019b). STEM education research and development as a rapidly evolving and international field. 数学教育学报(Journal of Mathematics Education), 28(3), 42-44.

Li, Y., Froyd, J. E., \& Wang, K. (2019). Learning about research and readership development in STEM education: A systematic analysis of the journal's publications from 2014 to 2018. International Journal of STEM Education, 6, 19. https://doi.org/10.1186/s40594-019-0176-1.

Li, Y., \& Schoenfeld, A. H. (2019). Problematizing teaching and learning mathematics as 'given' in STEM education. International Journal of STEM Education, 6, 44. https://doi.org/10.1186/s40594-019-0197-9.

Li, Y., Wang, K. \& Xiao, Y. (2019). Exploring the status and development trends of STEM education research: A review of research articles in selected journals published between 2000 and 2018. 数学教育学报(Journal of Mathematics Education), 28(3), 45-52.

Lin, T.-J., Lin, T.-C., Potvin, P., \& Tsai, C.-C. (2019). Research trends in science education from 2013 to 2017: A systematic content analysis of publications in selected journals. International Journal of Science Education, 41(3), 367-387.

Margot, K. C., \& Kettler, T. (2019). Teachers' perception of STEM integration and education: A systematic literature review. International Journal of STEM Education, 6, 2. https://doi.org/10.1186/s40594-018-0151-2.

Minichiello, A., Hood, J. R., \& Harkness, D. S. (2018). Bring user experience design to bear on STEM education: A narrative literature review. Journal for STEM Education Research, 1(1-2), 7-33.

Minner, D. D., Levy, A. J., \& Century, J. (2010). Inquiry-based science instruction what is it and does it matter? Results from a research synthesis years 1984 to 2002. Journal of Research in Science Teaching, 47(4), 474-496.

Mizell, S., \& Brown, S. (2016). The current status of STEM education research 20132015. Journal of STEM Education: Innovations \& Research, 17(4), 52-56.

National Research Council. (2012). Discipline-based education research: Understanding and improving learning in undergraduate science and engineering. Washington DC: National Academies Press.

National Science Foundation (1998). Information technology: Its impact on undergraduate education in science, mathematics, engineering, and technology. (NSF 98-82), April 18-20, 1996. http://www.nsf.gov/cgi-bin/ getpub?nsf9882 Accessed 16 Jan 2018
Raju, P. K., \& Sankar, C. S. (2003). Editorial. Journal of STEM Education: Innovations \& Research, 4(3\&4), 2

Ring-Whalen, E., Dare, E., Roehrig, G., Titu, P., \& Crotty, E. (2018). From conception to curricula: The role of science, technology, engineering, and mathematics in integrated STEM units. International Journal of Education in Mathematics, Science and Technology, 6(4), 343-362.

Schreffler, J., Vasquez III, E., Chini, J., \& James, W. (2019). Universal design for learning in postsecondary STEM education for students with disabilities: A systematic literature review. International Journal of STEM Education, 6, 8 . https://doi.org/10.1186/s40594-019-0161-8.

Schwab, D. B., Cole, L. W., Desai, K. M., Hemann, J., Hummels, K. R., \& Maltese, A. V. (2018). A summer STEM outreach program run by graduate students: Successes, challenges, and recommendations for implementation. Journal of Research in STEM Education, 4(2), 117-129.

Sochacka, N. W., Guyotte, K. W., \& Walther, J. (2016). Learning together: A collaborative autoethnographic exploration of STEAM (STEM+ the Arts) education. Journal of Engineering Education, 105(1), 15-42.

Sokolowski, A., Li, Y., \& Willson, V. (2015). The effects of using exploratory computerized environments in grades 1 to 8 mathematics: A meta-analysis of research. International Journal of STEM Education, 2, 8. https://doi.org/10. 1186/s40594-015-0022-z.

Thibaut, L., Ceuppens, S., De Loof, H., De Meester, J., Goovaerts, L., Struyf, A. Pauw, J. B., Dehaene, W., Deprez, J., De Cock, M., Hellinckx, L., Knipprath, H., Langie, G., Struyven, K., Van de Velde, D., Van Petegem, P., \& Depaepe, F. (2018). Integrated STEM education: A systematic review of instructional practices in secondary education. European Journal of STEM Education, 3(1), 2.

Tsai, C. C., \& Wen, L. M. C. (2005). Research and trends in science education from 1998 to 2002: A content analysis of publication in selected journals. International Journal of Science Education, 27(1), 3-14.

United States Congress House Committee on Science. (1998). The state of science, math, engineering, and technology (SMET) education in America, parts I-IV, including the results of the Third International Mathematics and Science Study (TIMSS): hearings before the Committee on Science, U.S. House of Representatives, One Hundred Fifth Congress, first session, July 23, September 24, October 8 and 29, 1997. Washington: U.S. G.P.O.

Vasquez, J., Sneider, C., \& Comer, M. (2013). STEM lesson essentials, grades 3-8: Integrating science, technology, engineering, and mathematics. Portsmouth, $\mathrm{NH}$ : Heinemann.

Wu, S. P. W., \& Rau, M. A. (2019). How students learn content in science, technology, engineering, and mathematics (STEM) through drawing activities. Educational Psychology Review. https://doi.org/10.1007/s10648-01909467-3.

Xu, M., Williams, P. J., Gu, J., \& Zhang, H. (2019). Hotspots and trends of technology education in the International Journal of Technology and Design Education: 2000-2018. International Journal of Technology and Design Education. https://doi.org/10.1007/s10798-019-09508-6.

\section{Publisher's Note}

Springer Nature remains neutral with regard to jurisdictional claims in published maps and institutional affiliations.

\section{Submit your manuscript to a SpringerOpen ${ }^{\circ}$ journal and benefit from:}

- Convenient online submission

- Rigorous peer review

- Open access: articles freely available online

High visibility within the field

- Retaining the copyright to your article

Submit your next manuscript at $\boldsymbol{\sim}$ springeropen.com 